\title{
ARQUITECTURA EN LA LAGUNA: EL CONCEPTO VERNÁCULO. CRITERIOS DE PROTECCIÓN Y EL PAPEL DEL DIBUJO
}

\author{
María Isabel Navarro Segura*, Fermín Delgado Perera** \\ Dácil Perdigón Pérez*** \\ Universidad de La Laguna
}

\section{RESUMEN}

La necesidad de dotar de base científica y técnica los criterios de protección en la catalogación del patrimonio arquitectónico en actividades del planeamiento ha requerido la creación de unas categorías de análisis y unos términos interpretativos de los valores patrimoniales del término municipal de San Cristóbal de La Laguna, que, por haber jugado un papel determinante en la historia de Canarias desde la conquista, permite desarrollar un glosario amplio referido a la arquitectura producida en la isla de Tenerife, también aplicable al conjunto de Canarias. Específicamente la arquitectura vernácula ha merecido una atención especial mediante la creación de una terminología específica y el reconocimiento del dibujo como herramienta de análisis.

PALABRAS ClAVE: catalogación, planeamiento, arquitectura, arquitectura vernácula, arquitectura moderna.

\section{ARCHITECTURE IN LA LAGUNA: THE CONCEPT OF THE VERNACULAR. CRITERIA OF PROTECTION AND THE ROLE OF THE DRAWING}

\section{Abstract}

The need to provide scientific and technical basis for protection criteria in the cataloging of the architectural heritage in urban planning activities has required the creation of analysis categories and interpretive terms of the heritage values of the San Cristóbal de La Laguna municipal district, which having played a decisive role in the History of the Canary Islands since the Conquest, has allowed us to develop a broad glossary referring to the architecture produced on the Island of Tenerife, also applicable to the Canary Islands as a whole. Specifically, the vernacular architecture has deserved special attention, through the creation of a specific glossary of terms and trough the recognition of drawing as an analytical tool.

KEYwORDs: catalog, urban planning, architecture, vernacular architecture, modern architecture. 


\section{EL INTERÉS POR LOS ESTUDIOS DE ARQUITECTURA VERNÁCULA: LA EVOLUCIÓN DEL CONCEPTO ${ }^{1}$}

La primera gran obra que reconoció el fenómeno de la arquitectura del Archipiélago como propia del sistema de la cultura de Canarias y de la tradición se debió al profesor Fernando Gabriel Martín Rodríguez. Siendo referencia necesaria su publicación Arquitectura doméstica canaria, es obligado contextualizar el sentido originario de su aportación sobre el tema, porque aparte de su rigor académico apareció iluminada por el ideario de la contracultura. Especialmente, los aspectos propios de las culturas anónimas, de las identidades populares y de los sistemas colectivos de la cultura recorren esta obra, lejos de nostalgias románticas, como una reconstrucción fiel para reivindicar su reconocimiento patrimonial:

En síntesis [...] es una auténtica denuncia de la distorsión cultural que ha convertido a la arquitectura doméstica en objeto de estudio casi exclusivamente de los etnólogos. Constituye una superación del concepto nostálgico que tiende a identificar como únicos valores de la arquitectura anónima los de tipo sociológico, contemplando al detalle la problemática interna de su lenguaje según una estricta metodología, que dejando al margen la adjetivación innecesaria, contribuye a resaltar los auténticos valores del modo de construir canario ${ }^{2}$.

Epígrafes decisivos tales como "Arquitectura culta y arquitectura popular», «Una arquitectura anónima», «Un modo canario»... ilustran el carácter de este estudio, que fue reconocido por el arquitecto ítalo-suizo Alberto Sartoris en algunas de sus publicaciones sobre la arquitectura canaria como una auténtica enciclopedia imprescindible para el conocimiento de esta arquitectura, que consideró como un

* Profesora de Historia del Arte de la Universidad de La Laguna. Departamento de Historia del Arte y Filosofía. Grupo de Investigación THACYGPA (HA). Correo electrónico: minavarr@ull. edu.es. Este trabajo se enmarca en el Proyecto de Investigación Revisión del Catálogo de Protección Arquitectónica del Plan General de Ordenación Urbana de San Cristóbal de La Laguna. Ayuntamiento de La Laguna y Fundación General de la Universidad de La Laguna (2017-18), bajo la dirección de la doctora M. ${ }^{a}$ Isabel Navarro. Investigadoras: Dácil Perdigón Pérez y Concepción Rodríguez Pérez; colaborador: Dr. Fermín Delgado Perera.

** Profesor de la Universidad Europea de Canarias. Colaborador del Proyecto. Correo electrónico: fermindelgadoperera@gmail.com.

*** Doctoranda por la Universidad de La Laguna e investigadora del Proyecto. Correo electrónico: dacilperdigon@gmail.com.

1 Martín Rodríguez, Fernando: Arquitectura doméstica canaria, Santa Cruz de Tenerife, 1978. Este artículo está dedicado al profesor Fernando Gabriel Martín Rodríguez, que impulsó los estudios científicos sobre la arquitectura vernácula de Canarias, y a la Revista de historia canaria, publicación en la que se ha hecho posible la investigación sobre Canarias y su cultura desde 1926 hasta su actual número 200.

2 Navarro Segura, María Isabel: «Martín Rodríguez, Fernando: Arquitectura doméstica canaria», Revista de historia canaria, tomo 37, año 48, número 172 (1980), pp. 287-289. 
capítulo fundamental de la arquitectura universal ${ }^{3}$. Al incluir la arquitectura de Canarias en este balance de la arquitectura universal, Sartoris se hizo eco del movimiento mundial interesado en las arquitecturas anónimas, que había evolucionado sensible desde la década de los años treinta. La crítica arquitectónica española se había interesado entonces en la arquitectura vernácula, en sus cualidades estéticas como propias de estéticas contemporáneas, de racionalidad, valores ecológicos...

Las revistas italianas impulsadas en los años treinta por los arquitectos Gio Ponti (Domus), Giuseppe Pagano (Casabella) o Giovanni Michelucci (Architettura) comenzaron a trabajar sobre los valores de la arquitectura vernácula y contribuyeron a su reconocimiento como arquitecturas esencialmente modernas. Sus revistas hermanas españolas fueron A.C., órgano del GATEPAC, o Gaceta de arte, que dedicaron artículos a la defensa de los valores intemporales de las arquitecturas vernáculas, condenando la revista de Tenerife las versiones decorativistas del regionalismo. Un nuevo significado se superpuso a esa revalorización en los años cincuenta, con el reconocimiento de las culturas del mundo, a través de la obra de Sibyl Moholy-Nagy ${ }^{4}$, y de las imágenes de la exposición Architecture without architects $^{5}$, del austríaco Bernard Rudofsky, en el MoMA de Nueva York. Esta labor, asociada a las actividades de la Unesco en el área de la cultura, ponía el acento en estas arquitecturas como imágenes de los pueblos desde una mirada esteticista en la que la fotografía tuvo un papel determinante.

Pero la recuperación de las arquitecturas populares en España durante los ańos setenta tuvo un carácter de redescubrimiento ligado a un sentido patrimonial nuevo, en parte a causa de los procesos de destrucción que tempranamente afectaron a amplias zonas transformadas por el turismo. El valor de los pueblos y sus culturas en trance de desaparición suscitó el interés por un tipo de estudios sistemáticos de carácter cientifista que en el caso español era novedoso. La contracultura que animó el debate internacional del momento se había interesado por la forma de vida autónoma y autogestionaria, en comunidad, de las sociedades rurales. En ese contexto, en Estados Unidos en los años setenta apareció una publicación considerada el precedente de las informaciones hoy difundidas a través de recursos electrónicos. El Whole Earth Catalog (1969-1972) tenía una especial dedicación a la problemática del hábitat entonces desde la perspectiva de la ecología. El responsable de la sección «Habitats» era el carpintero Lloyd Kahn, que en Shelter-abrigo-aludía al interés de difundir los recursos necesarios para cambiar la vida humana conquistando cotas de libertad posibles en medios rurales. La publicación, en gran formato y tiradas de más de 100000 ejemplares con abundante ilustración gráfica, era capaz de reproducir todos los detalles de variadas soluciones construidas de las más diversas culturas que habían permitido la autonomía de las formas de vida tradicionales.

3 Alberto Sartoris (1901-1998), doctor honoris causa por la Universidad de La Laguna (1993). Sartoris, Alberto: «L'architecture canarienne», en Présence de l'Architecture, Milano, 1986. pp. 175-186.

${ }^{4}$ Moholy-Nagy, Sibyl: Native Genius in Anonymous Architecture, New York, 1957.

${ }^{5}$ Rudofsky, Bernard: Architecture without architects, New York, 1964. 
La cuestión de la arquitectura tradicional, popular o rural había alcanzado interés en España desde los años treinta, cuando se analizaba la arquitectura popular del mundo como aquella dotada de las características de racionalidad pura en razón de sus cualidades de economía de recursos y adaptación al medio, siendo capaz de dar respuesta a las funciones humanas mediante el máximo grado de adecuación a la finalidad de su existencia y con un resultado esencial en cuanto a su imagen. A pesar de haberse estudiado en España esta arquitectura como «arquitectura popular» (Torres Balbás, Feduchi, García Mercadal, Giese, Flores...) ${ }^{6}$, pues se consideraba que estaban adscritas exclusivamente a contextos rurales, los estudios más recientes abandonan este término, o también el de «arquitectura tradicional», o «rural», demostrando su inequívoca presencia en ámbitos urbanos y en general, como tradición intemporal.

En su lugar, desde finales de los años sesenta y particularmente a raíz de algunas campañas propiciadas por la Unesco con la finalidad de garantizar el conocimiento y la conservación de estas arquitecturas se propició el empleo del término «arquitectura vernácula». El adjetivo vernáculo consta en la enciclopedia Larousse como un adjetivo aplicado a la arquitectura en sus primeras versiones, procedentes del latín vernaculum. En la enciclopedia de d'Alembert y Diderot (1765) se incluyó la palabra Vernaculaire definida como... «adjetivo. Es una palabra que se aplica a todo lo que es particular de un país. Ver Local». Más recientemente, en el siglo Xx, al desarrollarse los estudios sobre las culturas del mundo y su patrimonio, se aplicó este concepto de arquitectura vernácula a las arquitecturas populares. El Diccionario Larousse se hace eco de ello y define así vernáculo: «Didact. Propio de un país, de sus habitantes. Sinónimos. autóctono, doméstico, indígena. Indumentarias autóctonas. Con la agricultura, el tejido y la cerámica (...) A esta etapa pertenecen la mayor parte de las construcciones «vernáculas» realizadas en el mundo»?

Por su significado estricto, la arquitectura vernácula hace referencia a las construcciones realizadas en Canarias, y en particular en la isla de Tenerife, en la fase de colonización de la Isla y durante su historia hasta el periodo de la Edad Moderna. Es una manifestación del sistema de la cultura anterior a la normalización de las actividades artísticas derivada de la creación de las academias de bellas artes y a la difusión que alcanzaron los tratados. Al incorporarse a los concejos y entidades locales los nuevos titulados de la arquitectura dotados de formación conforme a la enseñanza reglada impartida por la Real Academia de Bellas Artes, se produjo un

${ }^{6}$ Estas publicaciones se vieron precedidas por la primera obra que aborda la arquitectura española con perspectiva científica y desde el punto de vista de la Historia de la arquitectura, que define exclusivamente la arquitectura civil aristocrática, LAMPÉrez, Vicente: "Arquitectura civil española de los siglos I al XviII». Tomo I. Madrid 1922. El error de Lampérez consistió en considerar que la arquitectura culta, en general, por contar con aspectos sometidos a propuestas de tratados y ejecuciones de artistas, no guarda relación con los sistemas propios de la arquitectura vernácula.

7 La Grande Encyclopédie, Paris, Larousse, tomo 16, 1973, p. 3255, col. 1. 
prototipo de arquitectura sometida a reglas de composición y normalización de elementos.

Según Erich Mercer:

Las construcciones vernáculas son las que pertenecen a un tipo comúnmente extendido en una zona determinada en una época dada. De ello se desprende que este tipo de construcción puede, en una misma época, ser 'vernácula' en una zona y 'no vernácula' en otra, y, en una misma zona, pasar, con el tiempo, de 'no vernácula' a 'vernácula'. Dicho de otro modo, una construcción es 'vernácula' o 'no vernácula' no debido a las características que le son propias, sino en virtud de las que comparte con otras muchas, y la identificación de las construcciones 'vernáculas' está en función de su importancia numérica relativa ${ }^{8}$.

\subsubsection{La casa «tradicional»}

La expresión "arquitectura tradicional», en general asociada en exclusiva a usos domésticos y rurales, fue la interpretación original de los estudios primeros sobre el fenómeno, en los que se contemplaba como pertenecientes a la "tradición" desde la perspectiva de la ruptura provocada por los cambios en la producción de la arquitectura sometida a nuevos procesos productivos ligados a la industrialización, y especialmente a comienzos del siglo xx. El rápido abandono de las técnicas, materiales y diseños provocó el punto de vista por el que estos procesos se analizaban desde una perspectiva dialéctica como opuestos al mundo contemporáneo.

El rasgo de la continuidad característica de los procesos de estas arquitecturas, transmitidas mediante un sistema de conocimientos, modelos y formas de vida generacionales de manera continuada es el que también explica el punto de vista original de los estudios sobre el fenómeno. Este enfoque fue comparable al que había experimentado la arquitectura académica al proporcionar patrones de producción sometidos a reglas a partir de finales del siglo XVIII y especialmente durante el siglo XIX, contemplando con idéntica distancia las arquitecturas de los siglos precedentes. En ese periodo se reconstruyeron buena parte de los ejemplares de las arquitecturas del Antiguo Régimen para proporcionarles condiciones de ornato y confort propias de los «tiempos modernos». Son intervenciones tradicionales.

Las recuperaciones realizadas a partir de los años setenta se apoyan en procesos de identificación con la autenticidad de las culturas locales, por lo que a la original referencia a la arquitectura tradicional o arquitectura popular se añade entonces la denominación de «arquitectura canaria». Su esencia es propiamente vernácula entendiendo el término como la definición de los tres elementos de conformación de un prototipo: el sistema de ocupación del parcelario, el sistema constructivo y el tipo

${ }^{8}$ Mercer, Erich: English Vernacular Houses. A study of traditional farmhouses and cottages, Royal Commission on Historical Monuments, London, Her Majesty's Stationery Office, 1975, Introducción, pp. 1-7. [Versión española, M.I. Navarro]. 
edificatorio, y, finalmente, la fachada como aportación urbana. Todas las arquitecturas producidas hasta el siglo XVIII desde ese punto de vista son vernáculas, tanto la arquitectura civil pública como la arquitectura religiosa y la propia arquitectura civil privada de uso residencial o mixto.

Este es el mito de la «Arquitectura de país»-entendiendo país como el contexto local y autonómico identificado con el ejemplar aludido-, porque coincide con un proceso de estudios sistemáticos para profundizar en los rasgos propios más que en identificar los rasgos compartidos con culturas de amplia implantación geográfica. En otras lenguas, como en el francés, la palabra campesino-paysan- tiene en su raíz la propia palabra país-pays-, por lo que también se usa en los vocablos de otros países la expresión casa campesina como casa de país.

En España ha sido tradicional el empleo de la expresión «arquitectura popular» porque se identifica con la vertiente de la palabra que conecta con demos-el pueblo- y al mismo tiempo se identifica con la variedad de las manifestaciones de las arquitecturas del país en los ámbitos campesinos. De este modo, se refleja la tendencia que excluye la arquitectura del Antiguo Régimen, que responde a procesos propios de la arquitectura culta y se encuentra tanto en ámbitos rurales como urbanos. Estas precisiones son imprescindibles porque la recuperación de las arquitecturas tradicionales, populares o de los lugares - por ejemplo, canaria- ha tenido un sentido arqueológico en los años treinta del siglo xx, un sentido ideológico a partir de los años cuarenta, y ya en los años setenta un sentido programático vinculado a las identidades.

En la actualidad los procesos de recuperación de estas arquitecturas vienen motivados por las nuevas competencias asumidas por los territorios autonómicos como garantes de la conservación de los bienes intergeneracionales tales como los concernientes a los valores culturales. En este sentido, el estudio y la conservación de la arquitectura producida históricamente en sus diversos episodios responde a la obligación de su recuperación en términos de autenticidad y desde una perspectiva científica, así como al objetivo de devolver su 'verdad construida'. Este objetivo es fundamental teniendo en cuenta la confusión provocada por el hecho de que a lo largo de los siglos, estas arquitecturas han requerido reconstrucciones que se hicieron abundantemente durante el siglo XIX para someterlas a renovaciones según los procesos de la Real Academia, abandonándose entonces las estructuras campesinas por otras que permiten a las capas populares acceder a viviendas en mejores condiciones.

Por otra parte, la existencia de relaciones geopolíticas cambiantes a lo largo de los siglos obliga a contemplar estos fenómenos desde una perspectiva transversal dado que, por una parte, los modelos de producción en Canarias proceden de ciclos hispanos y europeos y, por otra parte, en los procesos evolutivos posteriores a la primera implantación de la arquitectura en Canarias, y concretamente en San Cristóbal de La Laguna, se produjeron fenómenos de intercambio presentes en ambas orillas traduciendo un sistema de fronteras abierto, propio de la condición insular. La necesidad de definir un prototipo propio no contradice la posibilidad de estudiar variaciones locales especialmente en territorios tan variados como los que contempla el término municipal de La Laguna, con asentamientos en altura, en llano y núcleos costeros con usos de habitación muy diversos. Todo ello obliga a 
definir las categorías que por su número y su mantenimiento a lo largo del tiempo responden a un periodo de construcción inicial o reconstrucción hasta la última versión aparecida en la zona.

\subsubsection{Arquitectura vernácula. Definiciones}

Los ejemplos de supervivencia de la arquitectura vernácula pueden ser definidos a través de conceptos de la historia, la sociología y la técnica.

Historia. La arquitectura vernácula representa grupos de edificios que se producen durante un periodo de actividad de construcción y puede incluir periodos de reedificación identificables al tiempo que se extiende por amplias zonas pudiendo caracterizar ámbitos regionales de gran amplitud e incluso variadas zonas. La amplitud de sus ciclos también caracteriza los periodos temporales de la actividad de construcción cubriendo, con algunas variaciones correspondientes a los ciclos de las corrientes culturales, amplios periodos que llegan a duraciones superiores al siglo en ocasiones. Un edificio vernáculo nace en un momento histórico dado y termina igualmente de manera notoria al depender de procesos de construcción ligados a la obtención de tipos de materiales determinados y a una producción asociada a una formación por transmisión de saberes tradicionales. La incidencia más general es su conservación en estado original, aunque en ocasiones se conservan de manera parcial o son absorbidos por construcciones posteriores.

Sociología. Los tipos vernáculos se prolongan en el tiempo y reflejan los cambios en los ciclos económicos en periodos prolongados que abarcan épocas particulares de la historia cultural y manifiestan la estructura social promotora de su construcción, productora y usuaria al mismo tiempo. Las clases más elevadas socialmente producen ejemplos que perviven desde periodos más antiguos a causa de la calidad de los materiales y las técnicas empleados en su realización. Por este motivo, contrariamente a esta incidencia en las clases elevadas, las clases populares y en general los productos de los miembros de los niveles inferiores en la escala social difícilmente resisten el paso del tiempo y tienden a conservarse ejemplares más recientes. Los ejemplos más antiguos requieren la recuperación mediante procesos arqueológicos debido a la ausencia de referencias documentadas.

Tecnología. El sentido regional de amplias zonas con particularidades locales es la característica propia de la arquitectura vernácula. En esos límites se produce la difusión de formas de plantas, procesos constructivos y detalles estilísticos que superan los límites de la propia zona geográfica o «región», y se extienden en fronteras internacionales. La cualidad reconocible de los procesos propios de la arquitectura vernácula permite identificar periodos con un alto grado de precisión, con pequeños matices de variación según los procesos locales. En este contexto, la sistemática reconstrucción científica de la arquitectura canaria que se inició en los años setenta merece una paralela reconstrucción actual desde puntos de vista complementarios para garantizar la fidelidad de los procesos de protección patrimonial, y esa labor requiere una categorización desde el punto de vista de los procesos de incorporación de las arquitecturas a los distintos sistemas de ocupación y a través del tiempo. 
Además, la reconstrucción contemporánea del valor originario de la arquitectura requiere una recuperación de los elementos originales que solamente es posible en la actualidad a través de un proceso de dibujo desde el original, una suerte de arqueología arquitectónica que garantice por lo menos la existencia inmaterial de esta obra construida a través del tiempo.

\section{MÉTODOS DE ANÁLISIS Y CRITERIOS DE PROTECCIÓN DE LA ARQUITECTURA VERNÁCULA EN LA LAGUNA}

La siguiente relación de conceptos y métodos de análisis define los criterios de protección relativos a las arquitecturas históricas vernáculas en diferentes medios, tanto urbanos como rurales, que permitan reconocer las diversas categorías en las que prevalece el reconocimiento de los valores paisajísticos de la arquitectura en Canarias? Son conceptos que definen tipos, tipologías y modelos de ocupación del territorio:

\subsection{INSERCIÓN EN EL MEDIO AMBIENTE CON DOS VARIANTES}

\subsubsection{Tipos}

Responde a los procedimientos de organización de la isla de Tenerife en el Antiguo Régimen en la clasificación de ciudad, villa, pueblo, aldea... y la consideración actual distinguiendo entre los tipos urbano, suburbano y rural.

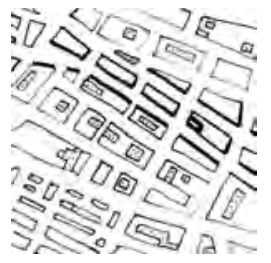

1. Edificio/Casa urbana: hace referencia a la implantación de ejemplares de arquitectura en contextos reconocidos como ciudad o en asentamientos tradicionales en los que hay un núcleo consolidado de habitación con un viario próximo representativo de la escala urbana.

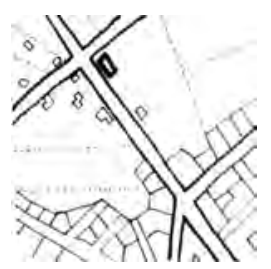

2. Edificio/Casa suburbana: construcciones en áreas con usos residenciales en proximidad a núcleos urbanos o asentamientos tradicionales. En algunos casos responden a la finalidad de organizar actividades especializadas sometidas a control en el contorno urbano, especialmente, en usos agrarios de heredamientos y pagos de viñas, o en actividades ganaderas, así como para usos productivos de materiales de construcción (tejeros, aserraderos...).

${ }_{9}$ Esta clasificación se ha realizado como metodología para la elaboración de criterios de valor en la revisión del catálogo de protección arquitectónica del municipio de La Laguna. Los gráficos ilustran las categorías para contribuir a una definición visual y conceptual. Son obra del Dr. Fermín Delgado Perera, colaborador del Equipo de Investigación. 


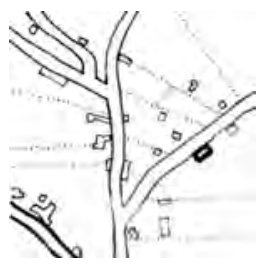

3. Edificio/Casa rural: corresponde a las arquitecturas en asentamientos de suelo rústico, en suelo agrícola en diseminado y también en modalidades de asentamientos tradicionales, así como en terreno estructurado en suertes agrícolas en conexión con caminos.

\subsubsection{Contextos}

Distingue entre aislada, en adosado y entre medianeras. Y además, las variantes en contacto con vías urbanas, en contacto con vías interurbanas y en contacto con camino. Otros tipos de contextos son: en suerte agrícola, en entorno diseminado, en barranco en contacto con camino y en barranco en entorno diseminado.

\subsubsection{Aislada}

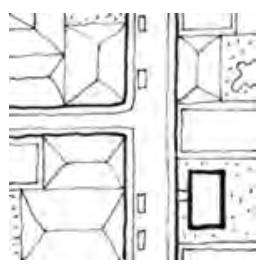

4. Aislada en contacto con vías urbanas: los edificios exentos en contacto con vías urbanas son prototipos significativos en los contextos de las periferias de los núcleos consolidados y pueden encontrarse igualmente en algunos ámbitos urbanos singularmente.

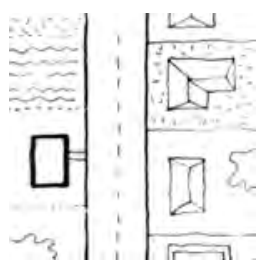

5. Aislada en contacto con vías interurbanas: los edificios exentos en contacto con vías interurbanas son prototipos frecuentes en las periferias urbanas y en contextos aislados.

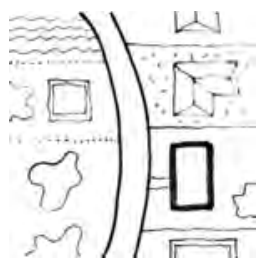

6. En contacto con camino: los edificios exentos en contacto con camino son prototipos frecuentemente tradicionales en ámbitos de estructura de propiedad agrícola o de reciente creación para uso residencial a la parcela en contacto con la vía. La estructura de la propiedad se mantiene a lo largo del tiempo.

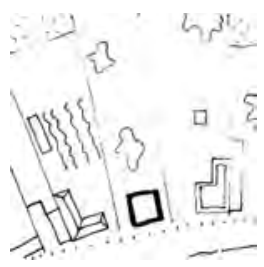

7. En suerte agrícola: son prototipos producidos en áreas en las que se transformó la estructura de la propiedad agrícola históricamente para dar lugar a una asignación de lotes de suelo a trabajadores que desarrollan su actividad en la propiedad adjudicada, en la que se ubica la vivienda en el acceso. 

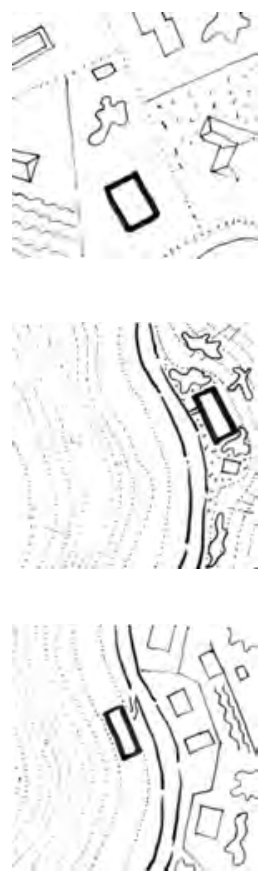

8. En entorno diseminado: prototipos presentes generalmente en ámbitos rurales, e igualmente en contextos propios de asentamientos tradicionales.

9. En barranco en contacto con camino: en los asentamientos tradicionales es frecuente la adaptación de las arquitecturas a las topografías accidentadas con acceso por camino, reservando el suelo útil para cultivos y explotaciones agrícolas.

10. En barranco en entorno diseminado: la implantación en barranco, aisladamente, es propia de los asentamientos tradicionales.

2.1.2.2. En adosado: en las variantes urbana, suburbana, rural, en contacto con camino, en suerte agrícola, en barranco...

2.1.2.3. Entre medianeras: igualmente en las variantes urbana, suburbana, rural, en contacto con camino, en suerte agrícola, en barranco...

\subsection{Arquitectura. Tipos/tipologías}

\subsubsection{Tipos}

Incluyen las variantes de organización arquitectónica: conjunto, heredamiento/hacienda de regadío y residencia, edificio/casa de una planta/casa terrera, edificio/casa alta/de dos o tres plantas, edificio/casa con cuerpos de diferentes alturas.

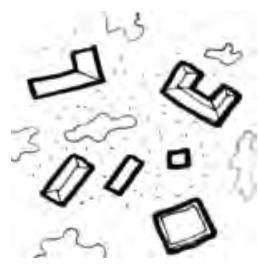

11. Conjunto: agrupación de varios inmuebles, en muchos casos de diferentes tipologías. Algunos pagos y aldeas presentan esta disposición, resultado de la presencia de tipos de explotación agrícola con modalidades de arrendamiento. 

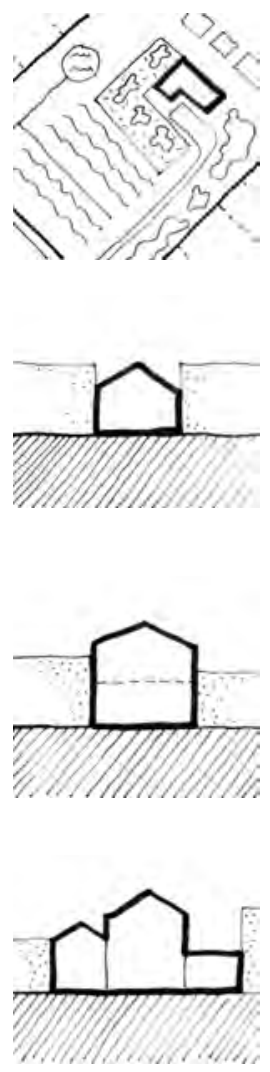

\subsubsection{Tipologías}

Incluyen las variantes de desarrollo volumétrico y funcional con sus modalidades de ocupación de parcela y distribuciones en planta.

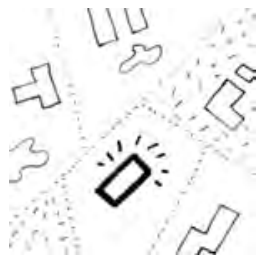

16. Edificio/casa en una pieza, en un solo bloque: unidad arquitectónica mínima de carácter tradicional, de uso residencial y/o agrícola. Puede tener variadas soluciones, tanto de adaptación al medio natural como de soluciones volumétricas y de distribución interior.

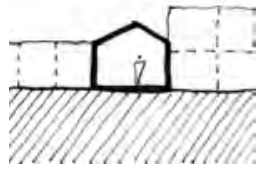

17. Edificio/casa una pieza, en un solo bloque, de una única habitación: es el caso más extendido en las arquitecturas de una planta. Son los casos más antiguos entre las construcciones vernáculas. 


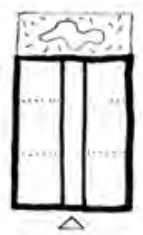

18. Edificio/casa en distribución axial con corredor central: modalidad de arquitectura tradicional con ocupación de la mayor superficie de parcela y con distribución en torno a pasillo central.

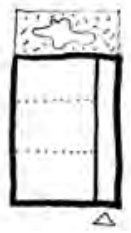

19. Edificio/casa en distribución axial con corredor lateral: modalidad de arquitectura tradicional con ocupación de la mayor superficie de parcela y con distribución en torno a pasillo lateral.

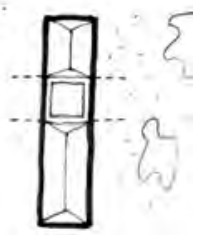

20. Edificio/casa en hilera: modalidad de arquitecturas en agregación de elementos en asentamiento adaptado a topografía. Es frecuente en los límites de las poblaciones y en ámbitos aislados con topografía accidentada.

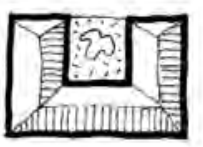

21. Edificio/casa en distribución en ele: sistema de agregación

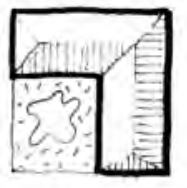
de elementos en torno a patio. La modalidad en ele es frecuente como solución de crecimiento de un edificio preexistente o como adaptación a determinadas condiciones del lugar en ámbitos rurales. Se encuentra igualmente en ámbitos urbanos.

22. Edificio/casa en distribución en u: fórmula de ocupación de parcela por agregación de varias crujías en torno a patio. Encierra grandes virtudes como solución de aprovechamiento del patio en contextos urbanos y también se encuentra en explotaciones agrícolas o viviendas de ámbito rural.

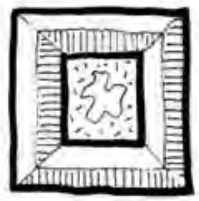

23. Edificio/casa en distribución con patio cerrado: modalidad de ocupación de parcela por agregación de crujías cerrando la edificación en torno a patio. Es la variedad de ocupación más intensa y corresponde a los episodios más avanzados de una edificación que se completa generalmente en el siglo XviII.

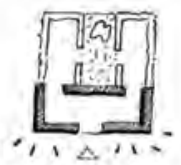

24. Edificio/casa con remodelación en fachada y primera crujía: a partir del siglo XVIII, con la aspiración de incorporar los lenguajes cultos a la arquitectura tradicional se realizan remodelaciones de crujías en fachada. 


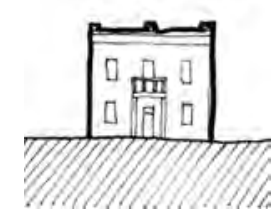

25. Hotelito: villa exenta como tipología residencial propia de las arquitecturas inspiradas en las villas clásicas y con desarrollo de lenguajes historicistas, eclécticos y vernáculos.

\subsubsection{Tipologias de la ciudad histórica de San Cristóbal de La Laguna ${ }^{10}$}

Las arquitecturas desarrolladas en la ciudad de San Cristóbal de La Laguna en el periodo fundacional son un caso peculiar por responder a un proceso de construcción de una ciudad nueva en un periodo de veinte años y bajo condiciones que han quedado documentadas. Según este procedimiento y las ordenanzas que le acompañaron, cada edificio construido en el contexto urbano tenía una componente residencial que podía acompańarse de diversas funciones complementarias propias del vecino que recibió la autorización para construir. Sin embargo, cada edificio debía contar con patio y huerto posterior, así como se definió igualmente la obligación de cultivar el huerto y plantar en él uva de parra con fines de autosubsistencia.

Este tipo de ocupación de la parcela refleja una evolución progresiva en horizontal hasta el final del límite de la propiedad, con la sucesiva definición de elementos añadidos al borde del patio, hasta alcanzar el perímetro final, y marcar la distinción entre una zona doméstica para usos de jardín, y una superficie trasera especializada en cultivos de huerta y árboles frutales, que podía contar con alguna estructura de granero en la fachada posterior de la vivienda en una planta sobradada, o situarse al fondo de la parcela. En este espacio cultivado solía también plantarse alguna parra para uva de mesa o pasas debido a una obligación contenida en las ordenanzas.

La arquitectura en La Laguna refleja el aspecto característico de las arquitecturas tradicionales, como tipos crecederos a partir de un método general, según el cual todos los ejemplares son casos particulares representativos de ese sistema. Así, desde la casa terrera del siglo XVI hasta los ejemplares de principios del siglo Xx, todas las edificaciones domésticas aparecidas en el callejero de La Laguna representan distintas fórmulas de creación de usos en el eje que transcurre desde el frente edificado a calle, en el segundo núcleo en torno a un patio, y en la relación de este espacio con el tipo de ocupación funcional en planta, y las variaciones tipológicas de uso/huerto posterior. Este concepto queda reflejado en los gráficos que siguen con el mismo tipo de planta y sus diferentes expresiones tipológicas.

${ }^{10}$ Definiciones establecidas en Navarro, M. ${ }^{a}$ Isabel: Expediente de Solicitud de Inscripción en la Lista del Patrimonio Mundial del Bien Cultural Conjunto Histórico de San Cristóbal de La Laguna, Ayuntamiento de San Cristóbal de La Laguna 1999. Se justificaron en la publicación que sirvió de referencia a la novedad científica definida en el expediente, Navarro Segura, María Isabel: La Laguna 1500: la ciudad-república. Una utopía insular según «las leyes» de Platón, La Laguna, 1999. 

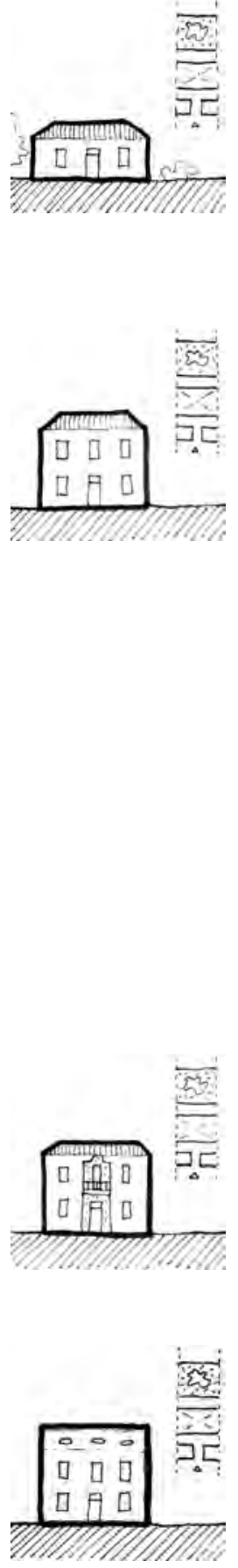

26. Edificio/casa terrera: modalidad de casa baja en parcela de pequeñas dimensiones, situada generalmente en el núcleo más antiguo de la ciudad. Suele tener una estructura asimétrica originalmente, incluyendo algunos huecos altos de pequeńas dimensiones para usos diversos de almacenamiento, o relacionada con la existencia de algunos oficios. Como en los restantes casos, se dispone en torno a un patio, y cuenta con una pequeña huerta o corral.

27. Edificio/casa alta o sobradada: denominación en documentos de la época, se refiere a la casa de dos plantas, aunque también puede aplicarse a edificios que llegan a alcanzar las tres plantas. El vocablo, de origen portugués -sobrado-, se refiere en realidad a cada una de las plantas que se construyen sobre la planta baja. Suele ser la «casa para vivir» característica del avecindado poseedor de tierras, que pone en renta sus tierras mediante diversos sistemas (complantación, aparcería, enfiteusis, medianías, soldadas...) y en alguna ocasión desempeña alguna otra actividad. La casa alta se reparte de manera homogénea por toda la trama urbana, y en la actualidad muestra soluciones de gran uniformidad, ya que muchas de ellas fueron sometidas a modificaciones puntuales en la distribución de huecos de fachada y remates durante el siglo XVIII y a lo largo del siglo XIX.

Esta modalidad de casa resulta indiferenciada en cuanto a su distribución. Las dependencias superiores suelen contar con galería en tres soluciones diferentes, combinando la disposición en ele, en u y con solución claustral. Las plantas superiores se mejoraron habitualmente con artesonados que varían según las épocas.

28. Edificio/casa armera: es la casa distribuida en las calles reales y en entornos de propiedades agrícolas singulares como signo de la importancia de sus moradores. Son conquistadores, y vecinos con títulos de Castilla, que recibieron importantes datas desde los primeros años. Pueden contar con más de una portada para la entrada de las bestias y carruajes o sillas de mano. En la planta inferior poseían las caballerizas y cocheras, bodegas y almacenes.

29. Edificio/casa granero: es el tipo más extendido en la villa. Aparecieron tempranamente en la ciudad como reflejo de la importancia de la actividad cerealista de su territorio. En los contratos se citan como troja o troje, también como çilla o tillero. Las tierras de pan llevar que se prolongaban hasta los terrenos de Los Rodeos permitían a los avecindados de San Cristóbal almacenar granos que aseguraban el sustento incluso en situaciones de carestía. 


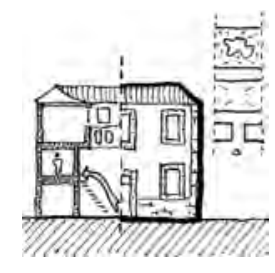

El sobrado destinado a granero se puede encontrar en pequeńas casas terreras a las que se añade una planta para esta finalidad. Sin embargo, los ejemplares más brillantes se encuentran entre los practicados en edificios reedificados con este fin y en construcciones a las que se ańade esta planta, alcanzando entonces las tres plantas, y manifestando exteriormente el carácter de casa funcionalmente adaptada a este uso. Suelen contar con una relación de elementos característicos: los tapaluces en las ventanas hacia la calle, para garantizar la oscuridad, los huecos bajo el tejado, que se deja sin vestir interiormente para permitir la ventilación constante, y los ventanales mediante elementos de corredera hacia el patio interior.

Suelen ser en ocasiones torreones que se distinguen del plano general de cubierta. Las fachadas se regularizan en el siglo XVIII, y pueden ser de tres huecos alineados en tres plantas, de cuatro y hasta de cinco huecos, las más importantes. Sin embargo, los más llamativos aparecen destacados mediante un balcón corrido de antepecho ciego y cubierto, que ocupa todo el frente de la tercera planta. Los huecos de esta tercera planta, dotados de tapaluces, suelen ser de menores dimensiones que los de la planta noble, $y$ en algunos ejemplares de la ciudad fueron modificados en el siglo XIX, dando lugar a una modalidad de huecos ovalados. En otros casos, los graneros se identifican en las fachadas traseras de las casas principales, al construirse como planta elevada el final del patio, sobre una galería cubierta.

30. Edificio/casa comercial: comienza por la modalidad de casa alta, o casa para vivir a la que se practica una entreplanta que suele coincidir con un lado del patio próximo a la primera crujía, junto al arranque de la escalera, una vez que se atraviesa el umbral del zaguán. Esta disposición permite organizar una circulación selectiva de accesos del público que visita la casa por razones comerciales o de tipo público, como en el caso de escribanos, bachilleres, comerciantes o cirujanos. La existencia de casas con esta estancia se constata en la villa desde 1509. Los ejemplos más antiguos corresponden al uso público de una parte de la vivienda, más que a actividades estrictamente comerciales. Estas dan lugar a una modalidad de casa de tres plantas, en la que la segunda de ellas puede destinarse a almacenamiento de ciertas mercancías y oficinas. La distribución más frecuente es la que arranca del descansillo de la escalera y se dispone en un lado del patio. Sin embargo, pueden darse ejemplos en ele, ocupando parte de la fachada principal, o llegar a ocupar dos lados del patio. El origen de este tipo comercial se ha situado en la Baja Andalucía, en localidades como Jerez, Puerto de Santa María 
y Puerto Real. Algunos casos obedecen a la transformación de edificios ya existentes para adaptarlos a nuevos usos, especialmente a partir de la segunda mitad del siglo XVII.

\section{DIBUJAR LA ARQUITECTURA VERNÁCULA}

Por medio del dibujo, la arquitectura puede llegar a ser una forma construida o existir solo como imagen. El dibujo y las implicaciones que ha tenido como herramienta de representación gráfica y analítica en la historia de la arquitectura es fundamental para entenderla y dejar memoria de ella. Sin embargo, en el caso particular de la arquitectura vernácula canaria -concretamente de La Laguna-, ha sido casi inexistente.

Este tipo de arquitectura es un modelo que se ha producido en el tiempo, no desarrollado a partir de planos dibujados, sino ejecutado a partir del conocimiento de la práctica constructiva, y es la propia obra la que actúa como un «documento» pues, al no estar dibujados, muchos ejemplos se han perdido por derribos o cambios posteriores.

Esta huella construida ha ido suscitando toda una serie de representaciones gráficas debido al interés que ha despertado en diferentes autores, en la mayoría de los casos ligada a la dimensión pictórica, dejando de lado aquella representación que usa el dibujo de arquitectura como instrumento de análisis y transmisor del conocimiento.

\subsection{El dibujo en ARQuitectura}

Según Jorge Sainz, el arquitecto expresa sus ideas y las comunica por tres vías: el lenguaje natural -vehículo de sus teorías-, el lenguaje gráfico -mediante sus dibujos- y el lenguaje arquitectónico -que se forja a partir sus obras $-{ }^{11}$.

Al igual que la disciplina arquitectónica tiende un puente entre el arte y la técnica, el dibujo de arquitectura -como lenguaje gráfico- posee también esta cualidad "fronteriza», tanto entre las propias artes como entre estas y la ciencia. Por ejemplo, el uso de la perspectiva desde el siglo XV al siglo XVII para vistas pictóricas de ciudades o fantasías varias muestra la relación de este tipo de dibujo con la pintura $^{12}$. Una variante intermedia -dialógica ${ }^{13}$ - entre la representación subjetiva y la científica se encuentra en los llamados «croquis analíticos»; huyendo de lo estrict-

${ }^{11}$ SAInz, Jorge: El dibujo de arquitectura. Teoria e historia de un lenguaje gráfico, Madrid, 1990, p. 21.

${ }^{12}$ Ibid., SAInZ, Jorge: op. cit., p. 12.

${ }^{13}$ Haciendo alusión a la filosofía del diálogo propugnada por Martin Buber (1878-1965). Véase Sánchez Mena, Diego: Buber (1878-1965), Madrid, 1997. 

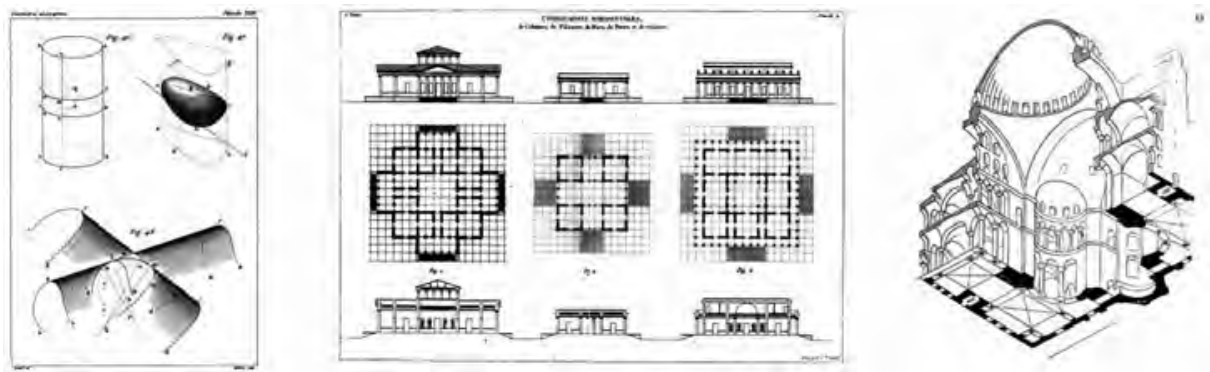

Fig. 1. Geometría descriptiva, lenguaje gráfico arquitectónico, y axonometría analítica. Izda.-der.: G. Monge (1799); J.N.L. Durand (1809); A. Choisy (1899).

amente geométrico y formal, mezclan lenguaje gráfico y elementos alfanuméricos, para representar mayormente aspectos funcionales o de zonificación ${ }^{14}$.

Para Rafael Moneo, el arquitecto siempre hará uso del «rasguño», usando el dibujo como medio inmediato para representar las ideas. Desde el Renacimiento, el dibujo ha sido el medio por el cual el arquitecto ha representado su obra mediante planos, e inmerso en el proceso constructivo, ha sido el instrumento de comunicación con los oficios involucrados y las instituciones pertinentes ${ }^{15}$.

Tres momentos destacan por su interés científico y analítico entre los numerosos episodios que ha vivido el dibujo arquitectónico [fig. 1]. A finales del siglo XviII (1798) se produjo un hecho determinante en la historia del dibujo: el matemático francés Gaspard Monge (1746-1818) estableció las bases de la geometría descriptiva, fundamentando así el dibujo científico en arquitectura a partir de proyecciones ortogonales, perspectivas y axonometrías ${ }^{16}$.

Otros dos autores dan fe de esta virtud científica. Por un lado, el arquitecto francés Jean-Nicolas-Louis Durand (1760-1834), que aboga por el dibujo arquitectónico como un «lenguaje de signos gráficos» por medio del cual explora su papel instrumental -mediante la planta, el alzado y la sección-y comunicativo, esto es, transmisor de contenidos arquitectónicos fuera de ambigüedades expresivas ${ }^{17}$. Por otro lado, el ingeniero francés Auguste Choisy (1841-1909) presenta un enfoque más analítico entendiendo el dibujo como una herramienta de investigación. En sus estu-

${ }^{14}$ Lapuerta, José María de: El croquis, proyecto y arquitectura [Scintilla divinitatis], Madrid, 1997, p. 61.

${ }_{15}$ Moneo, Rafael: «Idear, representar, construir». XI Congreso Internacional de Expresión Gráfica Arquitectónica. Funciones del Dibujo en la producción actual de Arquitectura, vol. III. Debates. Departamento de Expresión Gráfica Arquitectónica. Sevilla. 2007. Portfolio Internacional 1985-2012.

La Fábrica y CSCAE. Madrid. 2013.

16 SAInZ, Jorge: op. cit., p. 51.

17 Ibid., pp. 53-54. 
dios, presenta diferentes arquitecturas históricas analizadas e ilustradas, y para ello se basa principalmente en el dibujo axonométrico, que se presenta como un modelo de representación entre la perspectiva y el lenguaje gráfico a base de proyecciones ${ }^{18}$.

Sin embargo, en las últimas décadas del siglo $\mathrm{xx}$, el dibujo -como lo conocemos- ha perdido protagonismo en favor de los medios gráficos informatizados basados en el manejo de datos, que ofrecen una respuesta más automatizada debido al creciente protagonismo de las nuevas tecnologías. Aquí se encuentran las tecnologías CAD, BIM, el diseño paramétrico o el dibujo detrás de la denominada arquitectura diagramática ${ }^{19}$.

\subsection{Arquitectura vernácula Canaria, un mapa sin trazos}

Canarias, territorio de de interacciones culturales, constituyó tras la conquista el soporte territorial para una arquitectura vernácula que «no tiene aspiraciones teóricas ni estéticas; sus modelos se desarrollan de acuerdo a factores regionales, climáticos y económicos $\aleph^{20}$. Esta definición sobre lo vernáculo del arquitecto polaco Amos Rapoport (1929-), en el caso concreto de Canarias, sintoniza con el estudio de Fernando G. Martín Rodríguez cuando describe la "casa de las islas», para la cual «sin duda escogeríamos el apelativo de funcional. [...] donde lo accesorio es poco frecuente» ${ }^{21}$.

Aunque a principios del siglo xx esta arquitectura no llega a incluirse en los principales estudios clásicos de vivienda en el territorio español ${ }^{22}$, existe como tal y, según indica el arquitecto italiano Alberto Sartoris, no sale de la situación de sombra en la que se ha encontrado durante mucho tiempo -a pesar de existir publicaciones al respecto- hasta la aparición de «la obra capital de Fernando Gabriel Martín Rodríguez ${ }^{23}$. Sartoris, además, incluye en esta denominación la tradición arquitectónica de los pobladores primitivos, que no solo habitaron en cuevas, sino que en determinados casos crearon arquitecturas basadas en la yuxtaposición de elementos constructivos confeccionados en piedra y recursos vegetales ${ }^{24}$.

En un tiempo pasado, la arquitectura vernácula canaria se fue definiendo según las necesidades de sus habitantes, repitiendo modelos traídos de fuera pero adaptándolos al clima y a los materiales disponibles en el lugar, que posteriormente

18 SAINZ, Jorge: op. cit., p. 100.

19 Iто, Toyo. "Arquitectura diagrama», El Croquis, vol. 1, n. 77 (1996), pp. 18-24.

20 Rapoport, Amos, House form and culture, New Jersey, Prentice-Hall, p. 3 [versión castellana: Vivienda y cultura, Barcelona, GG, 1972].

21 Martín Rodríguez, Fernando G., Arquitectura doméstica canaria, Tenerife, 1978. p. 40.

22 Navarro Segura, Maisa (ed.): Alberto Sartoris: Magia de las Canarias, Las Palmas de Gran Canaria, 2003, p. 166.

${ }^{23}$ Idem.: "Rasgos esenciales de la vivienda canaria», en VV.AA.: Historia del arte en Canarias, Las Palmas, 1982, p.338.

${ }^{24}$ Ibid., pp. 106-107. De estas acciones quedan escasos «rastros» en la actualidad. Además, en la clasificación propuesta de la casuística doméstica del Catálogo de Protección de La Laguna, se incorporan aquellos casos ligados a la arquitectura doméstica de la cueva. 

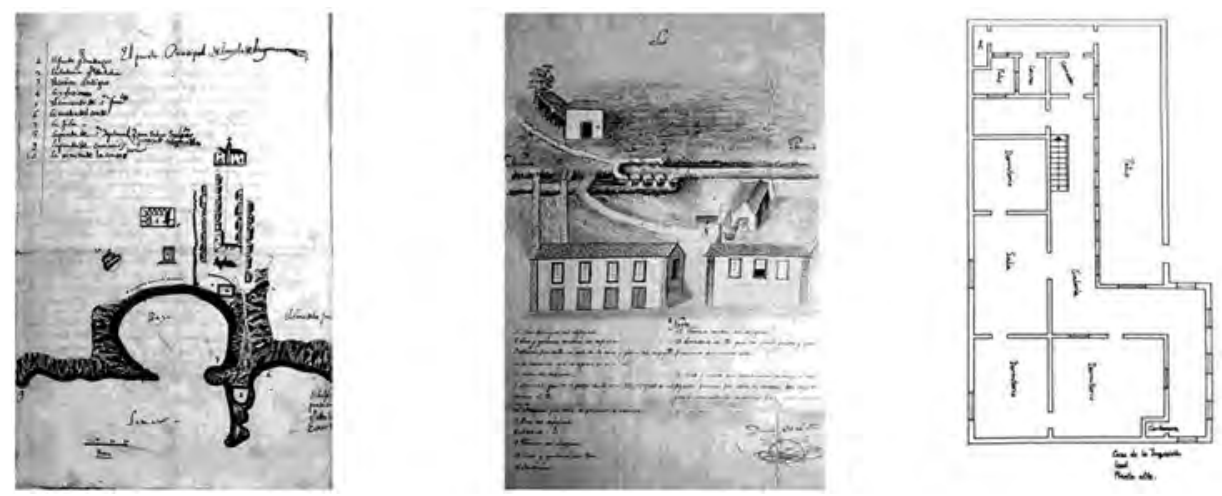

Fig. 2. Cartografía ingenieril, anexos gráficos referenciales, y estudios tipológicos. Izda.-der.: Lope de Mendoza (1666); S. Bello Artiles (1857-1859); F.G. Martín Rodríguez (1978).

serán mejorados en el tiempo ${ }^{25}$. Este conocimiento arquitectónico se transmitía de los «maestros» a los aprendices mediante la praxis, y no era recogido en ningún tipo de documentos mediante el dibujo de arquitectura, «ya que ante todo es una "arquitectura de la comunidad", no oficial, sino básicamente popular ${ }^{26}$. El hecho de no haber sido registrada mediante el dibujo ha generado la pérdida de ejemplos vernáculos, bien porque han desaparecido o porque han sufrido posteriores modificaciones.

Posteriormente, dicho paisaje construido ha generado imágenes diversas, interpretaciones de distintos autores con gran carga subjetiva, donde el protagonismo de la arquitectura ha ido fluctuando en dichas escenas a lo largo del tiempo.

\subsection{ACERCAMientos de CARÁCter Científico EN LA REPRESENTACión GRÁfiCa DE LA ARQUITECTURA VERNÁCULA CANARIA}

Analizando dicha producción gráfica basada en la «huella construida», no se detectan documentos con suficiente rigor científico hasta finales del siglo xx, aunque existen algunas modalidades de representación a lo largo de la vida de la arquitectura vernácula que de algún modo presentan cierta dosis de información analítica-científica sobre aspectos concretos de este tipo de arquitectura ${ }^{27}$ [fig. 2].

25 Alemán de Armas, Adrián: Elementos constructivos y ornamentales de la arquitectura en Canarias, Santa Cruz de Tenerife, Colegio Oficial de Aparejadores de Santa Cruz de Tenerife, 1968 , p. 2.

${ }^{26}$ Martín Rodríguez, Fernando G.: op. cit., p. 39.

${ }^{27}$ Hernández Gutiérrez, A. Sebastián: «La casa pintada: La arquitectura popular canaria y su representación gráfica», Rincones del Atlántico. Arquitectura y Paisaje. La arquitectura tradicional en el medio rural de Canarias, tomo 1, n. ${ }^{\circ}$ 5, 2008, pp. 258-359. 
Obviando las representaciones idílicas de los capellanes que acompañaron a los primeros conquistadores normandos a principios del siglo Xv, se puede detectar un primer grupo de representaciones de corte cartográfico realizadas por ingenieros que aúnan elementos geográficos característicos, asentamientos urbanos y la localización de edificios singulares -incluyendo leyenda, escala de medida y orientación-. Muestra de ello es el trabajo del ingeniero cremonés Torriani a finales del siglo XVI, donde aparece lo vernáculo formando parte de una imagen global urbana, pues centra su atención en la arquitectura de cierta importancia como iglesias y fortificaciones. Curiosamente, en uno de sus trabajos plasmó un ejemplo de lo que podría asemejarse a una perspectiva axonométrica seccionada de la arquitectura de los aborígenes ${ }^{28}$.

Esta falta de presencia y protagonismo de lo vernáculo en los documentos históricos se extiende hasta bien entrado el siglo XIX. Entre los siglos XVII y XVIII la representación gráfica que acompaña a esta arquitectura persigue fines «referenciales de localización" para tratar la problemática derivada de los límites de la propiedad del suelo. En estas representaciones también se pueden apreciar disposiciones edificatorias, orientaciones o leyendas informativas, y la arquitectura se simplifica: «... un cuadrado (el hábitat) soportaba un triángulo (la cubierta), y cuando el inmueble era una iglesia, sencillamente se le añadía una cruz en su vértice superior». Además, cabe incluir en este apartado las aportaciones en materia topográfica de visitantes europeos que usaron el territorio canario para la experimentación científica, y donde a la arquitectura del lugar es incluida como parte de la descripción dedicada a los pueblos allí encontrados ${ }^{29}$.

En adelante, «la situación cambiaría radicalmente con la llegada del siglo XIX y una renovación estética y filosófica aportada por el Romanticismo» ${ }^{30}$. Por consiguiente, la admiración por la belleza del paisaje captará toda la atención de los autores, y la arquitectura formará parte de imágenes que estampan escenas populares. Aquí se engloban modelos de representación que tienen a la arquitectura doméstica como motivo, bien dialogando solo con la domesticidad, o bien con el paisaje. Por ejemplo, los «libros de artista» a tinta en el caso de Diego Crosa o José Bernardo González Falcón, las acuarelas académicas de Francisco Bonnín Guerín y sus discípulos o, más recientemente, las visiones contemporáneas de Manolo Sánchez.

Un tercer grupo se podría denominar "tentativas investigadoras»" ${ }^{31}$, donde tendrían cabida aquellas representaciones que han tenido una actitud analítica, aunque careciendo de algún rasgo técnico ${ }^{32}$ del dibujo de arquitectura. La exploración

${ }^{28}$ Ibid., p. 260.

${ }^{29}$ Ibid., pp. 263, 266.

${ }^{30}$ Ibid., p. 268.

31 La primera aportación desde una perspectiva científica y etnográfica se debió a los viajeros europeos, y especialmente los científicos que visitaron Canarias, estudiados por Herrera PiQué, Alfredo: Las Islas Canarias, escala cientifica en el Atlántico: viajeros y naturalistas en el siglo XVIII, Madrid, 1987, tanto en esta obra como en diversas contribuciones.

32 SAINZ, Jorge: $o p$. cit., p. 74. El autor diferencia en el campo gráfico rasgos generales, intrínsecos, lógicos y técnicos (precisión, claridad o escala). 
crítica del arquitecto Alberto Sartoris -mediante textos y croquis analíticos de sus visitas a Canarias entre 1950 y 1965-incluye información del contexto y el «construir canario ${ }^{33}$, mostrando tanto aspectos tipológicos como del paisaje. En la publicación El caserío de Masca (1975), Adrián Alemán incluye proyecciones ortogonales de los inmuebles, pero no es hasta 1978 cuando Martín Rodríguez analiza -con un repertorio de dibujos técnicos- el lenguaje y las variantes de esta arquitectura, dibujando casos concretos de casas burguesas, y señalando, además, identidades morfológicas de la arquitectura popular, con especial atención a la ciudad de San Cristóbal de La Laguna.

Con todo ello se confirma que en el caso de la arquitectura vernácula de La Laguna, el dibujo no ha sido usado como instrumento de análisis con todo su potencial. La síntesis histórica de August Choisy realizada a través de axonometrías se perfila como un ejercicio de dibujo arquitectónico que permite analizar, describir y confrontar tanto aspectos arquitectónicos como técnicos y constructivos. Este ejercicio de representación sistemático, y con rigurosos datos e información científica, ha permitido representar la herencia de las principales arquitecturas históricas, mostrando así su valor patrimonial y la relación que la arquitectura guarda con el medio físico. Así, esta reflexión podría servir como punto de partida para futuras aproximaciones a la arquitectura vernácula canaria usando como instrumento analítico y de registro de la memoria el dibujo de arquitectura.

Recibido: 03-04-2018, ACEPTADO: 10-04-2018

33 Incluidos en Navar ro, Maisa (ed.): «Estudio introductorio», en Alberto Sartoris: Magia de las Canarias, Las Palmas de Gran Canaria, 2003. 
